\title{
Managerial Incentives and the Risk-Taking Behavior of Hedge Fund Managers
}

\author{
Serge Patrick Amvella Motaze ${ }^{1}$ \\ ${ }^{1}$ Finance Department, HEC Montreal, Montreal, QC, Canada \\ Correspondence: Serge P. Amvella Motaze, Finance Department, HEC Montreal, 3000 Cote Sainte-Catherine, \\ Montreal, QC, H3T 2A7, Canada. Tel: 1-514-340-6609. E-mail: serge.amvella@hec.ca
}

Received: December 27, 2012

Accepted: January 15, $2013 \quad$ Online Published: February 22, 2013

doi:10.5539/ijef.v5n3p36

URL: http://dx.doi.org/10.5539/ijef.v5n3p36

\begin{abstract}
We use a binomial model to derive the optimal trading strategy for a hedge fund manager facing different constraints such as the possibility of the fund liquidation and a minimum net-of-fees return to deliver in order to meet investors expectations. Our model enables us to link the optimal trading strategy and the optimal volatility of the fund to the management and incentive fee rates, the minimum net-of-fees return required by investors, the size of the fund and the moneyness of the option-like contract held by the manager. We find that even if the optimal volatility of the fund increases when the option is out of the money, there is a certain point at which it starts to decrease; and this point can vary from one manager to another given that it is related to factors such as his ownership in the fund and his tolerance for risk. These results give further insights on why some empirical studies such as Brown, Goetzmann and Park (2001) and Clare and Motson (2009) fail to find a general trend in hedge fund managers' risk-taking behavior when their option is out of the money.
\end{abstract}

Keywords: hedge funds, option-type compensation, high water mark, volatility, binomial model

\section{Introduction}

Several studies have addressed the issue of the risk-taking behavior of managers who have asymmetric compensation packages (incentive fees) and the conflicting results show how difficult it is to come up with a satisfactory answer. The incentive contract resembles a call option given that the manager receives incentive fees when the asset value exceeds the high water mark. Using a TASS database, Brown, Goetzmann and Park (2001) find that hedge fund managers tend to increase (decrease) risk in response to performance relative to their peers, but not in response to their absolute performance. They argue that the positive relationship between volatility and termination provides a disincentive for fund managers to gamble excessively when their option is out of the money (OTM). Carpenter (2000) examines the behavior of a mutual fund manager who has an option-like contract on the asset under management. She finds that the manager will increase the risk of the fund if the fund's return is below the hurdle rate and will decrease the risk if the return is above the hurdle rate, which also suggests a "locking in" behavior when the option-like contract is ITM. However, her analysis is over one period and ignores the possibility of the fund being liquidated in response to poor performance unless its value becomes zero. A liquidation boundary has been specified by other authors such as Goetzmann, Ingersoll and Ross (2003), Hodder and Jackwerth (2007) or Panageas and Westerfield (2009). Their models show that the manager has the incentive to increase risk given that the value of the option increases with the volatility, but as the fund's value approaches the liquidation boundary, the manager will decrease risk.

In this study, we use a binomial model to assess the risk-taking behavior of a hedge fund manager. As in Hodder and Jackwerth (2007), we present a theoretical and discrete time-model. Our approach enables us first to assess the impact that the level of volatility has on the expected manager's fees and the expected investors' wealth. Our results suggest the manager may not benefit from excessive risk-taking because a high level of volatility reduces the expected investors' wealth, which may lead to outflows when their objectives are not accomplished and therefore, may reduce the future compensation of the manager.

Second, we solve for the optimal trading strategy from the manager's prospect on a one-period basis. The one-period setting is justified because even though the manager's horizon is longer, he implements his optimal trading strategy period by period to maximize his compensation. He has an incentive to increase risk because his expected fees increase with volatility, while investors would like to inhibit excessive risk-taking because it 
impacts negatively on their expected wealth and increases the magnitude of potential losses. To account for this conflict of interest or agency problem, we derive the optimal trading strategy by setting first a liquidation boundary for the fund, and unlike previous studies, we add a constraint related to a minimum net-of-fees return to be delivered by the manager in order to renew his contract or avoid outflows due to poor performance. This constraint can be considered as a benchmark for the manager and shows that the fund should bear a minimum risk in order to meet investors' expectations in terms of returns. We also add a third constraint related to the manager' tolerance for risk. Our results show that the optimal allocation in the risky asset is negatively related to management and incentive fee rates, and to the size of the fund. However, it is positively related to the minimum net-of-fees return required by investors and to the moneyness of the option contract, the latter defined herein as the distance between the high water mark and the fund value. This means that the more the option is OTM, the higher the incentive to take risk will be. However, because of the liquidation boundary, there is a level of asset under management where the risk exposure of the fund starts to decrease.

The contribution of our paper to the hedge fund literature is to give further insights on the reason why the relationship between the volatility strategy of the manager and the moneyness of the option is complex especially when the latter is OTM. Indeed, Brown et al. (2001) and Clare and Motson (2009) fail to empirically find a clear behavior of hedge fund managers in response to absolute performance. Clare and Motson (2009) find that sometimes managers increase risk when their option is OTM, but they do not "put it all on black" in other to "win" back earlier losses. Our model shows that the manager increases the volatility up to a certain point when the fund is below the high water mark. Above this point, he decreases the volatility of the fund due to the fear of liquidation. This point depends on factors such as his tolerance for risk or his ownership in the fund and it is the reason why the risk-taking behavior will differ from one manager to another, and it will remain difficult to find a clear increase or decrease of risk when the option-like contract is OTM.

\section{The Model}

Compensation contracts for hedge fund managers include incentive fees which can be thought of as a call option on the portfolio that they manage. At the end of each period, the portfolio can take on a continuum of values. However, whatever the end value, there are only two possible outcomes: either the option is exercised or it is not The goal of this study is not to implement a sophisticated model that describes the precise portfolio value at the end of each period. Our study aims to model the two possible outcomes for the option through time. To achieve this, we use a binomial model. The binomial approach offers an intuitive and tractable setting for evaluating options, and provides results that are easy to interpret. It has the advantage of providing a closed-form solution for the optimal trading strategy and the optimal volatility of the fund.

The binomial model assumes that the asset value can either go up or down by a known amount and we use this approach for the intuition it offers in modeling the risk-taking behavior of the manager. Indeed, one can consider a binomial world setting where the manager bets on the market's direction. He can either win or lose. The initial size of the fund is $S_{0}$. We consider the problem of a hedge fund manager's optimal allocation of portfolio value into a risky and a riskless investment opportunity. The riskless asset grows at the risk free rate $r_{f}$ and has a volatility of zero, while the risky asset has a mean $\mu_{e}$ and a volatility $\sigma_{e}$. It follows a binomial random walk with the up and down parameters $u$ and $d$ defined as:

$$
\begin{aligned}
& u=1+\sigma_{e} \sqrt{T} \\
& d=1-\sigma_{e} \sqrt{T}
\end{aligned}
$$

The probability of a rise $p_{e}$ is defined as follows:

$$
p_{e}=\frac{1}{2}+\frac{\mu_{e} \sqrt{T}}{2 \sigma_{e}}
$$

and the probability of a fall is $1-p_{e}$. The choice of these constants is far from unique and we choose this specification for estimation purposes. (Note 1)

The manager selects a dynamic strategy by allocating a fraction $x_{e}$ of the fund in the risky asset and the remaining part $\left(1-x_{e}\right)$, is invested in the riskless asset. We allow the manager to control for $x_{e}$ which can be superior to 1 when he uses leverage. In that case he borrows at the risk free rate $r_{f}$. The asset under management $S$ follows a binomial random walk with a drift $\mu=x_{e} \mu e+\left(1-x_{e}\right) r_{f}$ and a volatility $\sigma=x_{e} \sigma_{e}$, and at the end of the evaluation period, its value $S_{T}$ can have two possible outcomes, either

$$
S_{T, u}=x_{e} S_{0}\left(1+\sigma_{e} \sqrt{T}\right)+\left(1-x_{e} S_{0}\right)\left(1+r_{f} T\right)
$$


or

$$
S_{T, d}=x_{e} S_{0}\left(1-\sigma_{e} \sqrt{T}\right)+\left(1-x_{e} S_{0}\right)\left(1+r_{f} T\right)
$$

The manager owns a fraction $a$ of the fund with $0 \leq a \leq 1$, and investors hold the remaining portion $(1-a)$ of the assets. Management fees equal a proportion $m \geq 0$ of fund value $(1-a) S_{T}$ at the end of the evaluation period and incentive fees are a percentage $k \geq 0$ of the fund's performance in excess of the high water mark $H_{T}$, that is (1-a)kmax $\left\{S_{T}-H_{T}, 0\right\}$. For some incentive contracts, the high water mark grows at a certain rate of interest. As Hodder and Jackwerth (2007), we assume that it grows at the risk free rate during the evaluation period such that $H_{T}=H_{0}\left(1+r_{f} T\right)$. The total wealth of the manager $W_{T}$ is the sum of his ownership in the fund and his fees. At the end of the evaluation period, it is expressed as follows:

$$
W_{T}=a S_{T}+(1-a)\left[m S_{T}+k \max \left\{S_{T}-H_{T}, 0\right\}\right]
$$

Investors wealth is expressed as follows:

$$
I_{T}=(1-a)\left[(1-m) S_{T}-k \max \left\{S_{T}-H_{T}, 0\right\}\right]
$$

From the above variables, the expected value of the manager's wealth at the end of the period is:

$$
E\left[W_{T}\right]=a E\left[S_{T}\right]+(1-a) m E\left[S_{T}\right]+k E\left[\max \left\{S_{T}-H_{T}, 0\right\}\right]
$$

From the binomial model, it follows that:

$$
\left.E\left[W_{T}\right]=a S_{0}(1+\mu T)+(1-a) \mid m S_{0}(1+\mu T)+k p_{e} \max \left\{x_{e} S_{0}\left(\sigma_{e} \sqrt{T}-r_{f} T\right)-L_{0}\left(1+r_{f} T\right), 0\right\}\right]
$$

with

$$
L_{0}=H_{0}-S_{0}, \text { the moneyness of the option. (Note 2) }
$$

We can note that $L_{0} \geq 0$ because the option is always either at the money $\left(H_{0}=S_{0}\right)$ or out of the money $\left(H_{0}>S_{0}\right)$ at the beginning of the year.

The expected investors' wealth is:

$$
E\left[I_{T}\right]=(1-a)\left[(1-m) S_{0}(1+\mu T)-k p_{e} \max \left\{x_{e} S_{0}\left(\sigma_{e} \sqrt{T}-r_{f} T\right)-L_{0}\left(1+r_{f} T\right), 0\right\}\right]
$$

The moneyness (or more precisely the "out of the moneyness") $L_{0}$ is an important variable of the model, because it determines how far the fund value is from the high water mark. In other words, it is a measure of how far the option is out of the money. This measure is interesting because it increases with previous losses and it shows the path-dependent nature of the manager's payoffs. The larger the value of $L_{0}$, the smaller the expected compensation of the manager.

\section{Impact of the Fund's Volatility Level on Expected Values}

Replacing the probability $p_{e}$ by its expression in equation (3), we obtain, depending on whether the option is expected to be exercised or not, the following expressions for the derivatives of $\mathrm{E}\left[W_{T}\right]$ and $\mathrm{E}\left[I_{T}\right]$ with respect to the volatility of the risky asset:

$$
\frac{\partial E\left[W_{T}\right]}{\partial \sigma_{e}}=\frac{1}{2}(1-a) 1_{k}\left[x_{e} S_{0} \sqrt{T}+\frac{\mu_{e} \sqrt{T}\left[x_{e} S_{0} r_{f} T+L_{0}\left(1+r_{f} T\right)\right]}{\sigma_{e}^{2}}\right]
$$

and 


$$
\frac{\partial E\left[I_{T}\right]}{\partial \sigma_{e}}=-\frac{1}{2}(1-a) 1_{k}\left[x_{e} S_{0} \sqrt{T}+\frac{\mu_{e} \sqrt{T}\left[x_{e} S_{0} r_{f} T+L_{0}\left(1+r_{f} T\right)\right]}{\sigma_{e}^{2}}\right]
$$

where $1_{k}$ is an indicator variable such that:

$1_{k}=k$ if the option is exercised

$1_{k}=0$ otherwise.

This shows that $\partial E\left[W_{T}\right] / \partial \sigma_{e} \geq 0$ and $\partial E\left[I_{T}\right] / \partial \sigma_{e} \leq 0$. The sensitivity of the expected manager's wealth and that of the expected investors' wealth with respect to volatility are equal in amplitude, but of opposite signs; the first being positive and the latter being negative. Then, for a given expected return, a higher level of risk has a positive impact on the manager's wealth. In fact, a high level volatility does not change the expected value of the manager's ownership in the fund, nor that of the management fees at time $T$. For a given expected return, these values remain constant whatever the level of volatility and we have $\partial E\left[a S_{T}\right] / \partial \sigma_{e}=0$ and $\partial E\left[\right.$ fess $\left._{T}\right] / \partial \sigma_{e}=0$. A higher level of volatility only increases the expected value of incentive fees because the distribution of the possible values of the option-like payoff is truncated at zero and we have $\partial E\left[W_{T}\right] / \partial \sigma_{e}=\partial E\left[\right.$ Ifess $\left._{T}\right] / \partial \sigma_{e}$. As a consequence, this reduces the expected investors' wealth of the fund by the same amount. The above equations show that the manager may have an incentive to increase risk, but if he has to choose between two assets having the same expected return, a rational manager will invest in the one with the lower volatility; because it has a better risk-adjusted return and also because even if investing in the asset with the higher volatility increases the expected value of his incentive fees, it reduces the expected value of investors wealth. If the manager wants to increase his fees, a solution is to increase the proportion of the fund invested in the asset with the best risk-adjusted return. This will increase the volatility of the whole fund as well as its expected return. As result, the manager will increase both the expected value of his wealth and the expected investors' wealth. The question is what is the optimal proportion to be invested in the risky asset, because increasing the risk of the fund also increases the magnitude of losses in the case where his bet does not come true.

\section{Other Factors That Can Impact the Manager's Risk-Taking Behavior}

The above results suggest that even if, a priori, we may have reason to believe that hedge fund managers have a strong incentive to take a high level of risk, especially when their incentive contract is OTM, they may not necessarily do so given the potential impact that it has on investors wealth. Furthermore, their volatility strategy may not only be driven by the willingness to exercise their option or to increase the value of their option contract, but also by other factors. Theory suggests that the value of an option increases with the volatility of the underlying asset. But this theory does not address the issue of overall wealth when the holder of the option is also the manager of the underlying asset, and this is the case for hedge fund managers. As Goetzmann et al. (2003) mention, hedge fund managers cannot do any form of delta hedging. They hold option-like contracts on assets they manage. If you hold an option contract on an underlying asset traded in the market, you will benefit from an increase in the volatility of the asset because it implies that your contract is worth more. However, if you have some interest in the underlying asset, you will be concerned by its risk level, and this is the case for hedge fund managers because a high volatility of the fund is also associated with a high probability of termination.

Many other factors may affect the risk-taking behavior of the manager such as his relative performance, his ownership in the fund, the size of the fund and the average risk of his peers. The various categories of hedge funds do not have the same exposure to risk factors and therefore, do not have the same level of risk. For instance, the average monthly volatility for Fixed Income Arbitrage funds in the TASS database from January 1994 to June 2011 was 2.60\%, while it was 5.93\% for Emerging Market hedge funds. (Note 3)

As for the size of the fund, incentive fees do not have the same importance in the manager's compensation. Incentive fees might be more important for a small fund because management fees (paid from the asset under management) might sometimes be insufficient to cover operating expenses. On the other hand, incentive fees might not be as important for a large fund which can cover its operating costs with management fees. Hence, a manager of a small fund is constrained to assume a higher level of risk in order to survive because for him, the 
relative importance of incentive fees is higher than it is for a manager of a large fund. As the fund grows, the relative importance of incentive fees decreases and thereby, the need to take riskier positions decreases.

\section{Optimal Trading Strategy}

The previous equations show that for a given expected return, a higher level of risk has a positive impact on manager incentive fees and a negative impact on investors wealth. On one hand, the manager has an incentive to manage a fund with a high level of risk because his option value at each period increases with volatility. On the other hand however, a higher volatility increases the magnitude of losses and this could be harmful to the manager's reputation as well as to his ownership in the fund and his compensation because of outflows due to bad performance. Outflows represent a powerful tool that investors can use in order to prevent excessive risk-taking by managers. Outflows lower managerial compensation because fewer assets under management imply smaller management and incentive fees. Outflows can also be costly for the manager because he could be forced to liquidate certain positions at a suboptimal price in order to meet redemptions. Outflows can even lead to the liquidation of the fund. The 2008 financial crisis is an example where many hedge funds have been forced to liquidate due to redemptions. In order to avoid withdrawals, and even attract new investments, the manager should maintain a good track record. For each period, he should provide the investor with a return after fees superior to that the latter can achieve on his own, otherwise he is better off investing elsewhere. Indeed, the reason why investors accept liquidity constraints imposed by hedge funds and the payment of high incentive fees is the strong expectation that year after year they will provide absolute returns. (Note 4)

Hedge funds define themselves as absolute-return strategies and a positive periodic return can be considered an implicit feature of the contract. This return may also depend on market conditions. For example, if we assume that the investor has the choice of investing in either a hedge fund or the risk free rate, this minimum return should be superior to the risk-free rate. Then, for each period, the manager faces a trade-off between increasing his fees and meeting investors expectations.

Now, let us solve for the optimal trading strategy of the fund from the manager's prospect. Let's denote $r_{b}$, the minimum net-of-fees return required by the investor, which in other words can be considered as a benchmark for the manager. As we mentioned, it may depend on market conditions, and we should have a specific $r_{b}$ for each period. We assume that $r_{b}$ is known at the beginning of each year and does not change during the year. Another assumption is that the fund can be liquidated in the event of a very poor performance as in Goetzmann et al. (2003) and Hodder and Jackwert (2007). Therefore, the manager should always watch the downside risk of the fund even if its expected return is positive. In our binomial model, a loss can occur with the probability $\left(1-p_{e}\right)$. An optimal behavior would be therefore to ensure that in the case of the occurrence of this state of nature, the value of the fund remains superior or equal to the liquidation boundary, otherwise the fund will be liquidated (immediately after the payment of management fees). Let's denote $B_{0}$, the liquidation boundary at the beginning of the year. (Note 5)

Another point to consider is the fact that in the three components of the manager's wealth, only the expected value of incentive fees increases with volatility as we mentioned previously. The expected value of management fees and that of his ownership in the fund does not change with a greater volatility. On the contrary, they will not necessarily benefit from a higher volatility because a higher level of risk also increases the magnitude of losses; and the higher the losses the lower this part of the manager's wealth will be. We then suppose that, according to his tolerance for risk, the manager sets a limit variance $\theta^{2}$ for this part of his wealth.

The manager's optimization problem is then to choose an admissible trading strategy that maximizes his expected wealth at the end of the evaluation period $T$, by using

$$
\left\{\begin{array}{cl}
\max _{x_{e}} & E\left[W_{T}\right] \\
\text { s.t. } & E\left[I_{T}\right] \geq I_{0}\left(1+r_{b} T\right) \\
& S_{T, d} \geq B_{0} \\
& \operatorname{Var}\left[a S_{T}+(1-a) m S_{T}\right] \leq \theta^{2}
\end{array}\right.
$$

The first constraint $(c 1)$ is related to the minimum net-of-fees return to achieve in order to meet investors expectation. If the performance of the fund is below this return, the manager exposes the fund to outflows. The 
second constraint (c2) is related to the liquidation boundary; if the value of the fund falls below $B_{0}$, this constraint will be violated, which will imply the liquidation of the fund. The third constraint $(c 3)$ is related to the limit volatility sets by the manager for the part of his wealth for which a higher volatility represents a higher risk, namely his investment in the fund plus management fees. Some critical values for $x_{e}$ follow from the three constraints:

- (cl) implies that, depending on whether the option is expected to be exercised, we should have $x_{e} \geq x_{c l}$ with

$$
x_{c 1}=\frac{S_{0}\left[\left(1+r_{b} T\right)-(1-m)\left(1+r_{f} T\right)\right]-\frac{1}{2} 1_{k} L_{0}\left(1+r_{f} T\right)\left(1+\frac{\mu_{e} \sqrt{T}}{\sigma_{e}}\right)}{S_{0}(1-m)\left(\mu_{e}-r_{f}\right) T-\frac{1}{2} 1_{k} S_{0}\left(\sigma_{e} \sqrt{T}-r_{f} T\right)\left(1+\frac{\mu_{e} \sqrt{T}}{\sigma_{e}}\right)}
$$

where $1_{k}$ is an indicator variable such that:

$1_{k}=k$ if the option is exercised

$1_{k}=0$ otherwise.

- (c2) implies that $x_{e} \leq x_{c 2}$ with

$$
x_{c 2}=\frac{S_{0}\left(1+r_{f} T\right)-B_{0}}{S_{0}\left(\sigma_{e} \sqrt{T}+r_{f} T\right)}
$$

- (c3) implies that $x_{e} \leq x_{c 3}$ with

$$
x_{c 3}=\frac{\theta}{\sigma_{e}[a+(1-a) m]}
$$

Then, $x_{c 1}$ represents the lower frontier for $x_{e}$, and $x_{c 2}$ and $x_{c 3}$ represent its upper frontiers. We can note that $x_{c l}$ is positively related to $r_{b}$, implying that the higher investors expectations in terms of return, the higher should be the investment of the fund in the risky asset. We can draw the frontiers inside which the manager can maximize his wealth without violating any of the three constraints. Figure 1 shows these frontiers if we assume the following values for the parameters: $\mu_{e}=0.08, \sigma_{e}=0.2, m=0.02, k=0.2, r_{f}=0.01, r_{b}=0.04, T=1, a=30 \%$, $\theta=0.14$, and $B_{0}=50 . H_{0}=100$ and the value of $S_{0}$ varies from 100 to 51 corresponding to a moneyness $L_{0}$ varying from 0 to 49 .

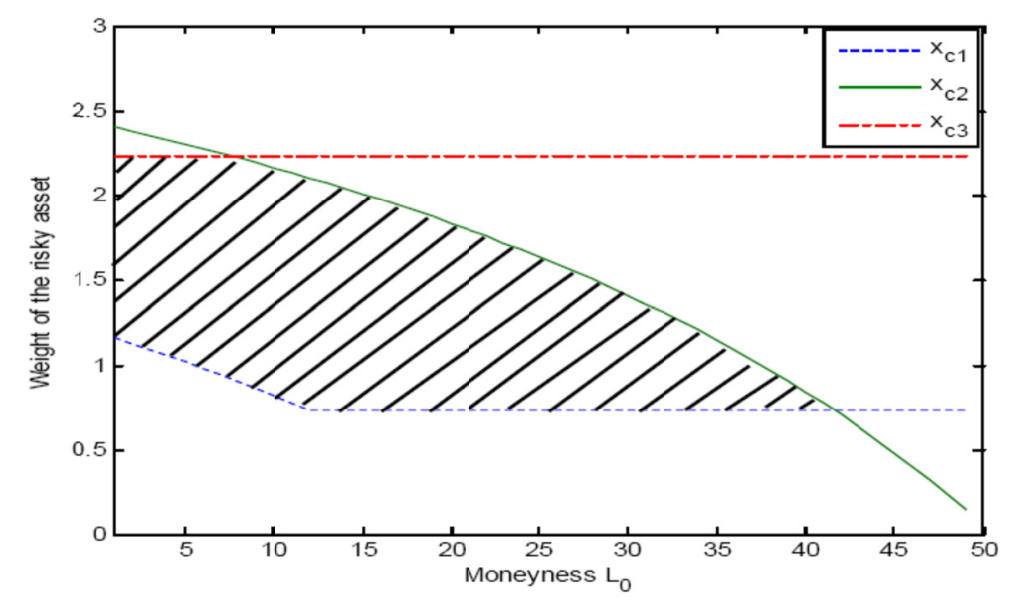

Figure 1. Frontiers for the risky asset weight related to constraints $c 1, c 2$ and $c 3$ and for different levels of moneyness

The dotted lines represent the frontier for (c1) and (c3), and the full and tiny line, the frontier for (c2). $x_{c l}$ corresponds to the weight at which the net-of-fees return of the fund is equal to the minimum required by 
investors. We can see that $x_{c l}$ decreases up to the point at which the option is expected to be exercised without violating constraint $(\mathrm{cl})$. This corresponds to a value of $S_{0}$ equal to 88 and a value of 12 for $L o$. Above this point, a lower weight for the risky asset implies a low volatility of the whole fund, insufficient to provide the minimum net-of-fees return required by investors. So, the manager should stop to decrease the allocation in the risky asset and $x_{c l}$ becomes constant. For this value of $x_{c l}$, the option is not exercised and the net-of-fees return of the fund is $r_{b}$.

Regarding $x_{c 2}$, we can see that it decreases as the moneyness $L o$ increases. This suggests that as the value of the fund decreases and gets closer to the liquidation boundary, the manager should reduce the investment in the risky asset. As for $x_{c 3}$, it remains constant and does not depend on the moneyness. The hatched area represents the area in which the manager can invest in the risky asset without violating any of the three constraints. We can see that beyond a certain level of moneyness it becomes impossible to invest without violating at least one of these constraints. In the present example, this level of moneyness is about 41 , which corresponds to a value of $S o$ equal to 59. Therefore, above this point, it is impossible to have an optimal solution.

The expression of $x_{c 3}$ in equation (14) shows that the more the manager is invested in the fund, the less $x_{c 3}$ will be. It is the only frontier that depends on the manager's stake in the fund and it shows how the manager's propensity of taking risk will be reduced with his involvement in the fund. Figure 2 shows the values of $x_{c 3}$ for values of manager stake equal to $10 \%, 20 \%$ and $30 \%$.

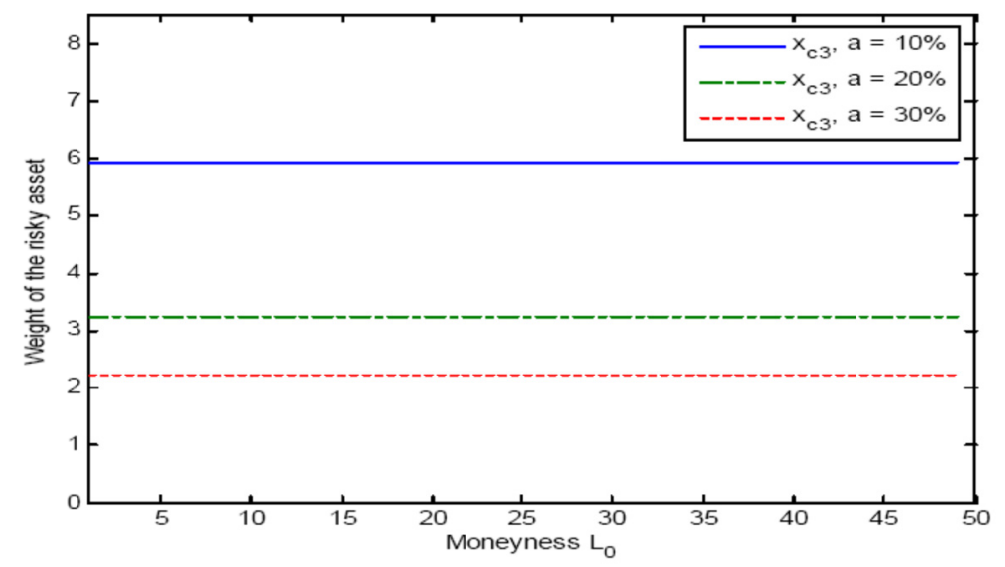

Figure 2. Frontiers related to constraint $c 3$ for different values of the manager's ownership $a$

We can see how $x_{c 3}$ decreases with the manager's stake in the fund. For instance, for $a=10 \%, x_{c 3}$ is almost equal to 6 , meaning that with a $10 \%$ ownership in the fund, and according to his tolerance for risk, the manager can be comfortable in investing a maximum of six times the value of the fund in the risky asset. This represents a leverage ratio of 5 . While for a $30 \%$ ownership, $x_{c 3}=2.23$, which reduces considerably the maximum investment in the risky asset.

Depending on the manager's stake in the fund, the upper limit for $x_{e}$ is $x_{c 2}$ or $x_{c 3}$. However, even if investing $x_{c 2}$ or $x_{c 3}$ in the risky asset provides the manager with the maximum wealth that he can expect without violating constraint 2 or constraint 3 , it does not necessarily represent the optimal trading strategy because it constitutes a very risky position. For instance, if the manager invests the proportion $x_{c 2}$ in the risky asset, the value of the fund will fall to the liquidation boundary if his bet does not come true and the survival of the fund will be threatened. So, the optimal investment in the risky asset is below $x_{c 2}$ or $x_{c 3}$ unless it is necessary. For example, suppose a certain amount of fees (management fees + incentive fees) for which the manager is comfortable, in other words, for which he can cover his operating expenses and remain with a certain profit. Then, the proportion of the fund that he will invest in the risky asset will be the one for which he can expect to earn this amount of fees. Let us denote this amount $v$. To solve for the corresponding weight in the risky asset, we have the following equation:

$$
(1-a) m E\left[S_{T}\right]+(1-a) k E\left[\max \left\{S_{T}-H_{T}, 0\right\}\right]=v
$$

The solution is 


$$
x_{v}=\frac{\frac{v}{(1-a)}-m S_{0}\left(1+r_{f} T\right)+\frac{1}{2} k\left(1+\frac{\mu_{e} \sqrt{T}}{\sigma_{e}}\right) L_{0}\left(1+r_{f} T\right)}{m S_{0}\left(\mu_{e}-r_{f}\right) T+\frac{1}{2} k\left(1+\frac{\mu_{e} \sqrt{T}}{\sigma_{e}}\right) S_{0}\left(\sigma_{e} \sqrt{T}-r_{f} T\right)}
$$

We can see that the above parameters impact differently on $x_{v}$ (the derivatives of $x_{v}$ with respect to these parameters are presented in the appendix):

- There is a negative relationship between $x_{v}$ and the incentive fee rate $k$. A higher $k$ implies a lower $x_{v}$ and a lower $k$ implies a higher $x_{v}$. This is consistent with Carpenter (2000) and shows that granting a high-incentive fee rate to the manager contributes to reducing his appetite for risk

- The same relationship exists between $x_{v}$ and the management fee rate $m$.

- There is a positive relationship between $x_{v}$ and the level of moneyness $L o$, implying that as the option goes out of the money, the manager should increase risk. Carpenter (2000) also finds a similar relationship.

- There is a negative relationship between $x_{v}$ and the asset under management $S o$. This corroborates what we said in the previous section; smaller funds will have more incentive to increase risk given the impact of the fund's size on the manager's compensation.

- Finally, there is a positive relationship between $x_{v}$ the manager's stake in the fund $a$, meaning that the more the manager is invested in the fund, the higher $x_{v}$ should be in order to earn the same level of incentive fees given that they are paid on a lower proportion of the fund $(1-a)$.

Figure 3 shows the values of $x_{v}$ for different levels of moneyness and for different values of $a$, when for example $v=5$. We can see how $x_{v}$ is an increasing function of $a$ and $L o$. As the moneyness increases, $x_{v}$ increases unboundedly.

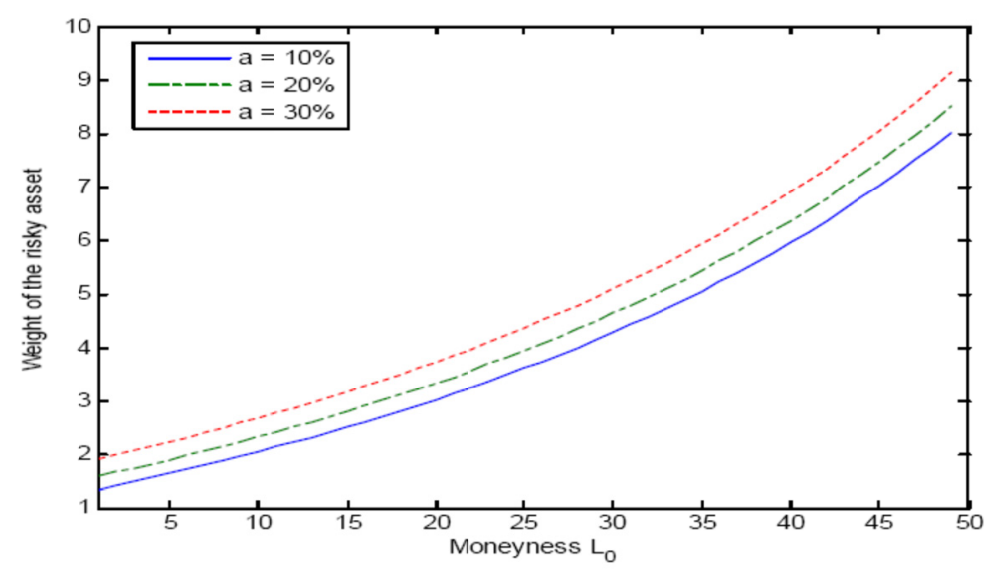

Figure 3. Values of the risky asset weight $x_{v}$ for $a=10 \%, a=20 \%$ and $a=30 \%$ and for different levels of moneyness

The relationship between $x_{v}$ and $a$ seems to be contrary to the conclusions of others studies which find that as the manager's ownership in the fund increases, his risk taking behavior is reduced. (Note 6) In fact, it is not the case because, as we showed earlier, $x_{c 3}$, which is related to manager's tolerance for risk, decreases with $a$; and $x_{c 3}$ prevails upon $x_{v}$ otherwise, constraint (c3) is violated.

So, even if $x_{v}$ increases with $a$, its maximum admissible value will be reached earlier for higher values of $a$ and as result, the manager's ownership in the fund will contribute to reduce his risk taking behavior. This is illustrated in figure 4 . 


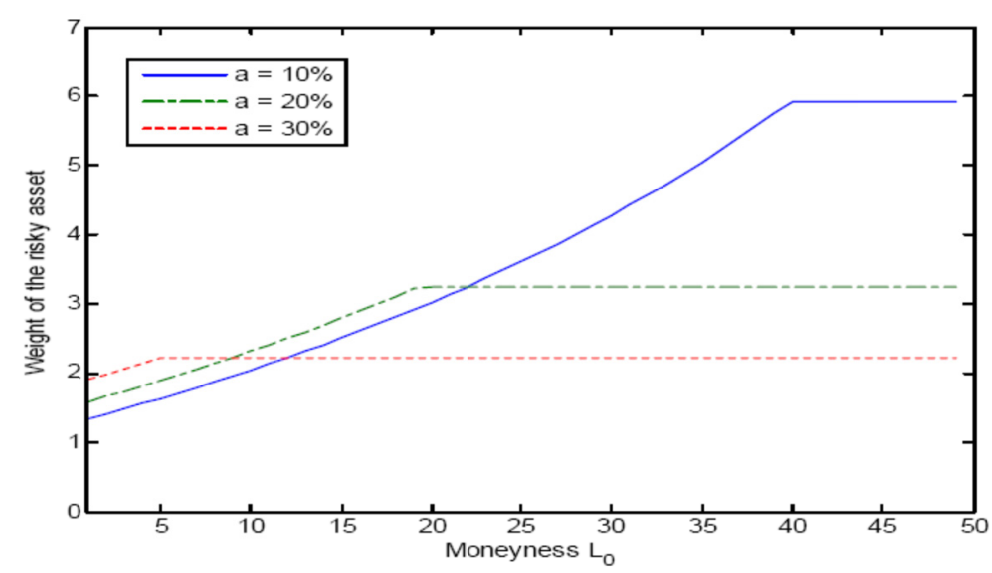

Figure 4. Values of the risky asset weight $x_{v}$ when constraint $c 3$ is taken into account

Moreover, as we mentioned previously, the optimal investment in the risky asset should not be superior to $x_{c 2}$ otherwise, constraint (c2) will be violated. Then, the manager will choose the lower of $x_{v}, x_{c 2}$ and $x_{c 3}$ to invest in the risky asset. In addition, $x_{v}$ should be superior or equal to $x_{c l}$ in order to fill the condition related to the minimum return $r_{b}$. Therefore, the optimal weight for which all the conditions are filled is:

$$
x_{e}^{*}=\max \left[x_{c 1}, \min \left(x_{v}, x_{c 2}, x_{c 3}\right)\right]
$$

We can then obtain the optimal volatility of the fund as follows:

$$
\sigma^{*}=x_{e}^{*} \sigma_{e}
$$

The sign of the relationship between $x_{e}^{*}$ and the parameters $k, m, S_{0}, L_{0}, a$ holds also for $\sigma$ and these parameters.

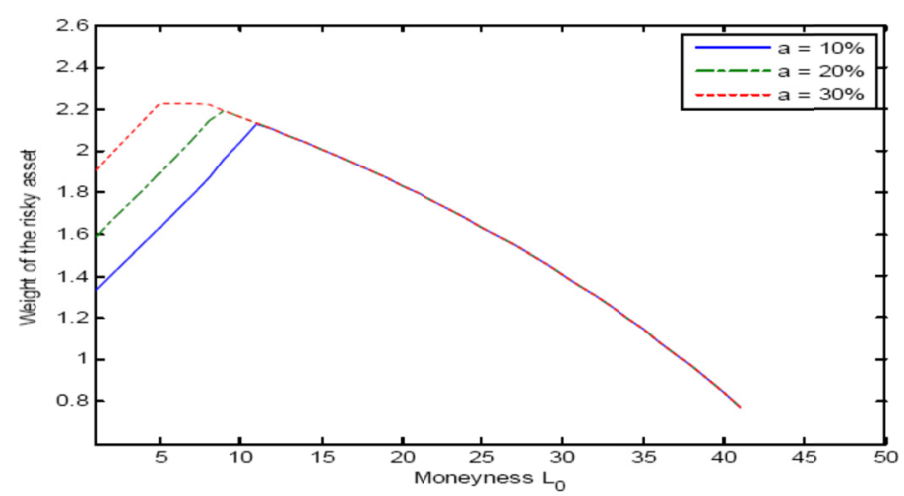

Figure 5. Optimal weight of the risky asset for $a=10 \%, a=20 \%$ and $a=30 \%$ and for different levels of moneyness 


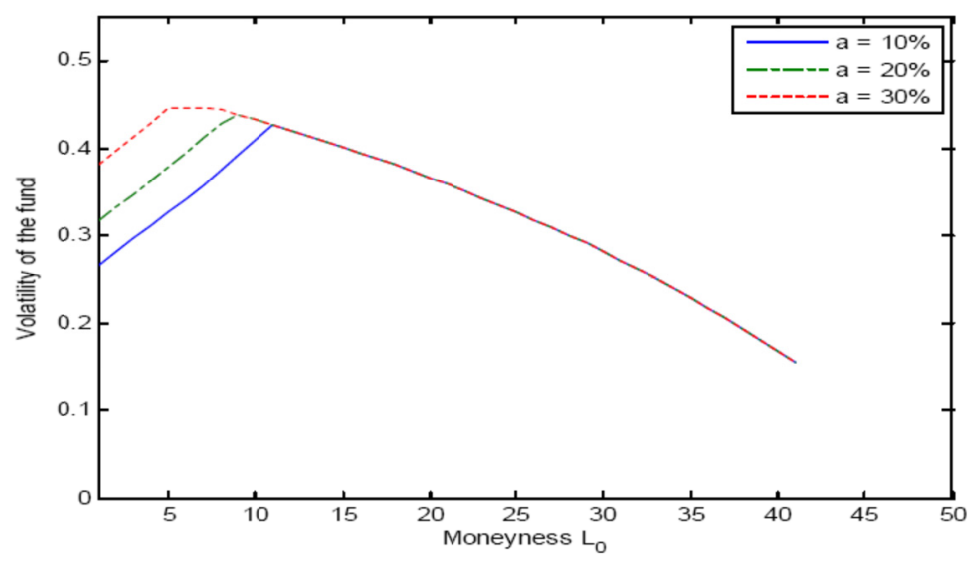

Figure 6. Optimal volatility of the fund for $a=10 \%, a=20 \%$ and $a=30 \%$ and for different levels of moneyness

Figure 5 and 6 represent the optimal proportion of the fund to be invested in the risky asset and the optimal volatility of the fund. We can see in figure 5 that for low values of the moneyness $L_{0}$, the manager increases the investment in the risky asset by using leverage as the probability of exercising his option-like contract is higher; and the higher his ownership in the fund, the higher the use of leverage. However, the manager starts to decrease the investment in the risky asset for some levels of moneyness and each of these levels depends on the value of $a$, his ownership in the fund. The higher his ownership, the earlier $x_{e}^{*}$ starts to decrease and for $L_{0}=11$, the investment in the risky asset becomes the same whatever the ownership of the manager. For $L_{0}=38$, the manager stop using leverage and starts to increase the investment in the risk free asset to reduce the whole risk of the fund given that asset value gets closer to the liquidation boundary. Beyond the value of $L_{0}=41$, it is impossible to invest without violating at least one of the constraints and it is therefore impossible to have an optimal weight for the risky asset beyond this value.

\section{Conclusion}

The option-like compensation contract of hedge fund managers serves as an incentive to superior performance. However, this particular form of manager compensation can also become an incentive to take more risk in order to end up with an incentive contract in the money. The purpose of this paper is to evaluate the optimal trading strategy for a hedge fund manager facing different constraints among others, the possibility of the fund liquidation or a minimum return to deliver in order to meet investors expectations. To this end, we use a binomial model and our analysis documents interesting findings.

First, we find that a high level of risk positively impacts the expected manager's incentive fees at the end of the period but negatively impacts the expected investors' wealth. With a one-year contract and with no investment in the fund, the manager's optimal behavior would be to maximize the value of his option-like contract by increasing the volatility of the fund infinitely if he does not have to meet investor expectations. However, the time horizon of the manager's contract is more than one year and he must make a trade-off between current and future payoffs because a high volatility level increases the magnitude of potential losses and a decline in the fund value also implies a decline in his overall future wealth.

Among other interesting results of our model, we find that even if the optimal volatility of the fund increases with the "out of the moneyness" of the option, there is a certain point at which the optimal volatility starts to decrease; and this point can vary from one manager to another given that it is related to factors such as his ownership in the fund and his tolerance for risk. This is consistent with Brown, Goetzmann and Park (2001) and Clare and Motson (2009) who document in empirical studies that it is difficult to find a general trend in hedge fund managers risk-taking behavior when their option is OTM.

The results of the present study suggest that incentive contracts, to the extent that they are long-term-oriented, are designed to encourage good performance. Our conclusions apply not only to hedge funds, but to any form of contract where the manager's compensation has an incentive feature. With a high water mark provision, as is the case for hedge funds, the incentive contract will be either at the money or out of the money at the beginning of each year. Each loss will contribute to increase the "out of the moneyness" of the option-like payoff and the greater the "out of the moneyness", the lower the expected fees of the manager. In this respect, the very form of 
hedge fund contracts contributes to lower the manager's appetite for risk because he earns incentive fees only after recovering past losses. With the absence of a high water mark provision, which is the case in many instances such as corporate executives compensation contracts, the option is at the money at the beginning of each year which does not help reduce the agency problem. Nowadays, where the compensation of corporate executives is increasingly called into question, hedge fund compensation contracts, although not perfect, could be a good source of inspiration.

\section{Acknowledgements}

The author is grateful to seminar participants at the 2009 NFA annual meetings in Niagara-On-The-Lake, the 2010 EFA meetings in Miami, for many helpful comments. I would also like to thank Nicolas Papageorgiou and Iwan Meier for their helpful comments. I gratefully acknowledge financial support by the Centre de Recherche en E-Finance (CREF), l'Institut de Finance Mathématique de Montréal (IFM2).

\section{References}

Agarwal, V., Daniel, N. D., \& Naik, N. (2009) Role of managerial incentives and discretion in hedge fund performance. Journal of Finance, 64, 1985-2428. http://dx.doi.org/10.1111/j.1540-6261.2009.01499.x

Brown, S. J., Goetzmann, W. N., \& Park, J. (2001). Careers and survival: competition and risk in the hedge fund and CTA industry. Journal of Finance, 56, 1869-1896. http://dx.doi.org/10.1111/0022-1082.00392

Carpenter, J. N. (2000). Does option compensation increase managerial risk appetite? Journal of Finance, 55, 2311-2331. http://dx.doi.org/10.1111/0022-1082.00288

Clare, A., \& Motson, N. (2009). Locking in the profit or putting it all on black? An investigation into the risk-taking behaviour of hedge fund managers. Working paper, The Cass Centre for Asset Management Research. Retrieved from http://www.cass.city.ac.uk/_data/assets/pdf_file/0006/69936/_Locking-in-the-profits-or-putting-it-all-on-bla ck.pdf

Goetzmann, W. N., Ingersoll, J. E., \& Ross, S. A. (2003). High-water marks and hedge fund management contracts. Journal of Finance, 58, 1685-1718. http://dx.doi.org/10.1111/1540-6261.00581

Hodder, J. E., \& Jackwerth, J. C. (2007). Incentive contracts and hedge fund management. Journal of Financial and Quantitative Analysis, 42, 811-826. http://dx.doi.org/10.1017/S0022109000003409

Kouwenberg, R., \& Ziemba, W. T. (2007). Incentives and Risk Taking in Hedge Funds. Journal of Banking and Finance, 31(11), 3291-3310. http://dx.doi.org/10.1016/j.jbankfin.2007.04.003

Panageas, S., \& Westerfield, M. M. (2009). High-water marks: high risk appetites? Convex compensation, long horizons, and portfolio choice. Journal of Finance, 64, 1-36. http://dx.doi.org/10.1111/j.1540-6261.2008.01427.x

Wilmott, P. (2006). Paul Wilmott on quantitative finance (2nd ed.). John Wiley \& Sons.

\section{Notes}

Note 1. For more information on the model, the reader can refer to the book Paul Wilmott On Quantitative Finance (2nd ed.), John Wiley \& Sons, 2006.

Note 2. See appendix for the demonstration. Equation (8) implies that if $x_{e} S o\left(\sigma_{e} \sqrt{ } T-r_{f} T\right)-L o\left(1+r_{f} T\right)>0$, the option is expected to be exercised. While if $x_{e} S o\left(\sigma_{e} \sqrt{ } T-r_{f} T\right)-L o\left(1+r_{f} T\right) \leq 0$, the option is not expected to be exercised.

Note 3. Data from TASS database.

Note 4. Agarwal, Daniel and Naik (2009) find a median lockup period of 1 year and a median redemption delay of 0.2 year on a merged database formed by CISDM, HFR, MSCI and TASS.

Note 5. It is not obvious to specify a liquidation boundary corresponding to the hedge fund industry because individual investors may have different rules for liquidation. Goetzmann, Ingersoll and Ross (2003) use different liquidation boundaries such that the investor will liquidate if the asset value falls by $5 \%$ or $20 \%$ from his personal high water mark. Hodder and Jackwerth (2007) assume that the fund is liquidated if the asset value falls by $50 \%$ from the high water mark.

Note 6. For instance, Kouwenberg and Ziemba (2007) or Hodder and Jackwerth (2007). 


\section{Appendix}

\section{A.1. Expected Values and the Derivates with Respect to Volatility}

From the binomial model we have:

$$
E\left[S_{T}\right]=S_{0}\left(1+\mu T_{e}\right)
$$

With

$$
\mu=x_{e} \mu_{e}+\left(1-x_{e}\right) r_{f}
$$

The expected value of the manager's wealth is expressed as follows:

$$
\begin{gathered}
E\left[W_{T}\right]=a E\left[S_{T}\right]+(1-a) m E\left[S_{T}\right]+k E\left[\max \left\{S_{T}-H_{T}, 0\right\}\right] \\
=a S_{0}(1+\mu T)+(1-a)\left[m S_{0}(1+\mu T)+k\left[\begin{array}{l}
p_{e} \max \left\{x_{e} S_{T, u}-H_{0}\left(1+r_{f} T\right), 0\right\} \\
+\left(1-p_{e}\right) \max \left\{x_{e} S_{T, d}-H_{0}\left(1+r_{f} T\right), 0\right\}
\end{array}\right]\right. \\
=a S_{0}(1+\mu T)+(1-a)\left[m S_{0}(1+\mu T)+k\left[\begin{array}{l}
p_{e} \max \left\{x_{e} S_{0}\left(\sigma_{e} \sqrt{T}-r_{f} T\right)-L_{0}\left(1+r_{f} T\right), 0\right\} \\
+\left(1-p_{e}\right) \max \left\{x_{e} S_{0}\left(-\sigma_{e} \sqrt{T}-r_{f} T\right)-L_{0}\left(1+r_{f} T\right), 0\right\}
\end{array}\right]\right.
\end{gathered}
$$

where $L_{0}=H_{0}-S_{0}$.

With $L_{0} \geq 0$ given that $H_{0} \geq$ So, we have:

$$
\left(1-p_{e}\right) \max \left\{x_{e} S_{0}\left(-\sigma_{e} \sqrt{T}-r_{f} T\right)-L_{0}\left(1+r_{f} T\right), 0\right\}=0
$$

and as result,

$$
E\left[W_{T}\right]=a S_{0}(1+\mu T)+(1-a)\left[m S_{0}(1+\mu T)+k p_{e} \max \left\{x_{e} S_{0}\left(\sigma_{e} \sqrt{T}-r_{f} T\right)-L_{0}\left(1+r_{f} T\right), 0\right\}\right]
$$

With $p_{e}=\frac{1}{2}+\frac{\mu_{e} \sqrt{T}}{2 \sigma_{e}}$, we obtain:

$$
E\left[W_{T}\right]=a S_{0}(1+\mu T)+(1-a)\left[m S_{0}(1+\mu T)+\frac{1}{2} 1_{k}\left[\begin{array}{l}
x_{e} S_{0}\left(\sigma_{e} \sqrt{T}+\left(\mu_{e}-r_{f}\right) T\right) \\
-L_{0}\left(1+r_{f} T\right)-\frac{\mu_{e} \sqrt{T}\left[x_{e} S_{0} r_{f} T+L_{0}\left(1+r_{f} T\right)\right]}{\sigma_{e}}
\end{array}\right]\right]
$$

where $1_{k}$ is an indicator variable such that:

$1_{k}=k$ if the option is exercised

$1_{k}=0$ otherwise.

Then, the derivative of with respect to the volatility of the risky asset is:

$$
\frac{\partial E\left[W_{T}\right]}{\partial \sigma_{e}}=\frac{1}{2}(1-a) 1_{k}\left[x_{e} S_{0} \sqrt{T}+\frac{\mu_{e} \sqrt{T}\left[x_{e} S_{0} r_{f} T+L_{0}\left(1+r_{f} T\right)\right]}{\sigma_{e}^{2}}\right]
$$

By the same way we have:

$$
E\left[I_{T}\right]=(1-a)\left[(1-m) E\left[S_{T}\right]+k E\left[\max \left\{S_{T}-H_{T}, 0\right\}\right]\right]
$$




$$
=(1-a)\left[(1-m) S_{0}(1+\mu T)-\frac{1}{2} 1_{k}\left[\begin{array}{l}
x_{e} S_{0}\left(\sigma_{e} \sqrt{T}+\left(\mu_{e}-r_{f}\right) T\right) \\
\left.-L_{0}\left(1+r_{f} T\right)-\frac{\mu_{e} \sqrt{T}\left[x_{e} S_{0} r_{f} T+L_{0}\left(1+r_{f} T\right)\right]}{\sigma_{e}}\right]
\end{array}\right]\right.
$$

Then, its derivative of with respect to the volatility of the risky asset is:

$$
\frac{\partial E\left[I_{T}\right]}{\partial \sigma_{e}}=-\frac{1}{2}(1-a) 1_{k}\left[x_{e} S_{0} \sqrt{T}+\frac{\mu_{e} \sqrt{T}\left[x_{e} S_{0} r_{f} T+L_{0}\left(1+r_{f} T\right)\right]}{\sigma_{e}^{2}}\right]
$$

\section{A.2. Derivatives of $x_{v}$ with Respect to Parameters $k, m, L_{0}, S_{0}$ and a}

$$
\begin{aligned}
& \left(^{*}\right) \frac{\partial x_{v}}{\partial k}=\frac{\frac{1}{2}\left(1+\frac{\mu_{e} \sqrt{T}}{\sigma_{e}}\right)\left[m\left(1+r_{f} T\right)\left[L_{0}\left(\mu_{e}-r_{f}\right) T+S_{0}\left(\sigma_{e} \sqrt{T}-r_{f} T\right)\right]-\frac{v}{(1-a)}\left(\sigma_{e} \sqrt{T}-r_{f} T\right)\right]}{S_{0}\left[m\left(\mu_{e}-r_{f}\right) T+\frac{1}{2} k\left(1+\frac{\mu_{e} \sqrt{T}}{\sigma_{e}}\right)\left(\sigma_{e} \sqrt{T}-r_{f} T\right)\right]^{2}}<0 \\
& \left(^{*}\right) \frac{\partial x_{v}}{\partial m}=\frac{-\left[\begin{array}{l}
S_{0}\left(1+r_{f} T\right)\left[m\left(\mu_{e}-r_{f}\right) T+\frac{1}{2} k\left(1+\frac{\mu_{e} \sqrt{T}}{\sigma_{e}}\right)\left(\sigma_{e} \sqrt{T}-r_{f} T\right)\right] \\
\left.+\left(\mu_{e}-r_{f}\right) T\left[\frac{v}{(1-a)}-m S_{0}\left(1+r_{f} T\right)+\frac{1}{2} k\left(1+\frac{\mu_{e} \sqrt{T}}{\sigma_{e}}\right) L_{0}\left(1+r_{f} T\right)\right]\right]
\end{array}\right.}{S_{0}\left[m\left(\mu_{e}-r_{f}\right) T+\frac{1}{2} k\left(1+\frac{\mu_{e} \sqrt{T}}{\sigma_{e}}\right)\left(\sigma_{e} \sqrt{T}-r_{f} T\right)\right]^{2}}<0 \\
& \left.{ }^{*}\right) \frac{\partial x_{v}}{\partial L_{0}}=\frac{\frac{1}{2} k\left(1+\frac{\mu_{e} \sqrt{T}}{\sigma_{e}}\right)\left(1+r_{f} T\right)}{S_{0}\left[m\left(\mu_{e}-r_{f}\right) T+\frac{1}{2} k\left(1+\frac{\mu_{e} \sqrt{T}}{\sigma_{e}}\right)\left(\sigma_{e} \sqrt{T}-r_{f} T\right)\right]}>0 \\
& \left(^{*}\right) \frac{\partial x_{v}}{\partial S_{0}}=\frac{-\left[\frac{v}{(1-a)}+\frac{1}{2} k\left(1+\frac{\mu_{e} \sqrt{T}}{\sigma_{e}}\right) L_{0}\left(1+r_{f} T\right)\right]}{S_{0}^{2}\left[m\left(\mu_{e}-r_{f}\right) T+\frac{1}{2} k\left(1+\frac{\mu_{e} \sqrt{T}}{\sigma_{e}}\right)\left(\sigma_{e} \sqrt{T}-r_{f} T\right)\right]}<0 \\
& \left.{ }^{*}\right) \frac{\partial x_{v}}{\partial a}=\frac{1}{(1-a)^{2} S_{0}\left[m\left(\mu_{e}-r_{f}\right) T+\frac{1}{2} k\left(1+\frac{\mu_{e} \sqrt{T}}{\sigma_{e}}\right)\left(\sigma_{e} \sqrt{T}-r_{f} T\right)\right]}>0
\end{aligned}
$$

